\title{
Multi-Objective Curing Cycle Optimization for Glass Fabric/Epoxy Composites Using Poisson Regression and Genetic Algorithm
}

\author{
Georgios Seretis $^{a *}$, Georgios Kouzilos ${ }^{a}$, Dimitrios Manolakos ${ }^{a}$, Christopher Provatidis ${ }^{a}$ \\ ${ }^{a}$ School of Mechanical Engineering, National Technical University of Athens, 9 Heroon Polytechniou \\ Str., 15780 Zografou, Athens, Greece
}

Received: September 07, 2017; Revised: November 10, 2017; Accepted: December 14, 2017

\begin{abstract}
In this study, a multi-parameter design of experiments, using Taguchi method, has been conducted in order to investigate the optimum curing conditions for glass fabric/epoxy laminated composites, followed by a statistical analysis and genetic algorithm optimization. Heating rate $a$, temperature $T_{l}$ and duration $h_{1}$ were treated as independent variables in a $\mathrm{L}_{25}$ Taguchi orthogonal array addressing five levels each. Tensile load and flexural strength were examined as pre-selected quality objectives. The results of the analysis of variance performed showed that the significant parameters for both tensile and flexural strength were temperature and duration, at a 95\% confidence level. The estimation of the curing parameters for optimum tensile and flexural performance was achieved with an error considerably lower than $1 \%$. The Poisson regression analysis was introduced to achieve a highly accurate regression model, with $R^{2}$ greater than $97 \%$ for both optimization criteria. Finally, these two regression models were converted into a two-fold function for maximizing both criteria, and used as fitness function for a multi-objective optimization genetic algorithm.
\end{abstract}

Keywords: Polymer-matrix composites, Laminates, Cure behavior, Mechanical properties, Poisson regression, Soft-computing.

\section{Introduction}

One of the most important processes for epoxy composites production is curing, since most of the final properties of the composites are controlled and affected by the curing cycle applied ${ }^{1,2}$. Many different parameters that affect the curing cycle and its results, such as the relation between the curing temperature $\left(T_{\text {cure }}\right)$ and the glass transition temperature $\left(T_{g}\right)^{3}$, have been widely investigated ${ }^{3-6}$. Alternative curing processes, such as curing using microwaves, have been studied as well ${ }^{7-10}$.

Taguchi analysis has been used in many cases to predict the response of composite materials, evaluate the significance of affecting parameters and calculate the optimum conditions/ parameters for various types of composite materials and related processes. A.Q. Barbosa et al. used a Taguchi design of experiments to understand the influence of each parameter under study (amount, size and presence of surface treatment) and the interaction between them ${ }^{11}$. The finite element (FE) simulation, the Taguchi technique, and the analysis of variance (ANOVA) techniques were carried out by Thipprakmas to investigate the degree of importance of V-ring indenter parameters ${ }^{12}$. A. K. Parida et al. applied response surface methodology (RSM) to determine the optimum machining conditions leading to minimum surface roughness in drilling of GFRP composite ${ }^{13}$. The experimental plan and analysis is based on the Taguchi $\mathrm{L}_{27}$ orthogonal array taking spindle speed (N), feed (f) and diameter of drill bit (d) as important parameters. Rout and Satapathy describe a Taguchi design methodology to determine optimal parameter settings in the development of multiphase hybrid composites consisting of epoxy reinforced with glass-fiber and filled with rice husk particulates ${ }^{14}$. R.A. Kishore et al. performed a Taguchi analysis of the residual tensile strength after drilling in glass fiber reinforced epoxy composites ${ }^{15}$. V.N. Gaitonde et al. investigated and analyzed the parametric influence on delamination in high-speed drilling of carbon fiber reinforced plastic composites ${ }^{16}$. Tsao and Hocheng investigated the delamination associated with various drill bits in drilling of composite materials using Taguchi analysis ${ }^{17}$. Davim and Reis investigated the drilling process on carbon fiber reinforced plastics manufactured by autoclave, performing an experimental study followed by a statistical analysis of the results ${ }^{18}$.

Several different methods have been used to analyze the influence of the curing parameters on the final properties of the produced composites. Full factorial approaches are the most commonly used although they employ limited number of levels for each factor, due to the considerably large number of experiments ${ }^{19,20}$. Some studies control only one factor per time, i.e. per experimental series ${ }^{21}$. The central composite rotatable design combined with a quadratic response surface model has been also used ${ }^{22}$. Finally, Taguchi design of experiments has been used combined mostly with linear or quadratic regression models ${ }^{11}$. 
The commonly used Multiple Regression Analyses are based on many different regression models ${ }^{23-28}$. Many efforts have been made in order to achieve a highly accurate multiple regression mode ${ }^{25,27-29}$. However, the widely used regression models are quite trivial and their accuracy is in many cases quite low ${ }^{11}$.

In order to investigate the optimum curing conditions for glass fabric/epoxy laminated composites, a multi-parameter design of experiments, using Taguchi method, has been conducted in this study, followed by statistical analysis and a genetic algorithm multi-objective optimization. In a $\mathrm{L}_{25}$ Taguchi orthogonal array, the parameters heating rate $a$, temperature $T_{1}$ and duration $h_{1}$ were treated as independent variables addressing five levels each. The quality objectives examined were tensile load and flexural strength. Flexural strength is of the most important and desired properties of fabric reinforced laminated composites ${ }^{30-32}$. However, composite structures often fail under flexural $\operatorname{load}^{32,33}$. Therefore, it is crucial to obtain the optimum flexural strength for these materials, since there is a constant need for their flexural performance improvement. Additionally, tensile performance is important to be optimized for all engineering materials. Analysis of variance results shown that the significant parameters for both tensile and flexural strength were temperature $T_{1}$ and duration $h_{l}$, at a $95 \%$ confidence level. The error of the estimation of the curing parameters for optimum tensile and flexural performance was considerably lower than $1 \%$. However, the widely used regression models achieved quite low accuracy. Therefore, the solution came from a regression analysis that is quite common in epidemiology, sociology and psychology, i.e. Poisson regression. Here, the Poisson regression analysis was introduced to achieve a highly accurate regression model, with $R^{2}$ greater than $97 \%$ for both optimization criteria. This accuracy has never reported using the widely used regression models. Finally, these two regression models were converted into a two-fold function for maximizing both criteria, and used as fitness function for a multi-objective optimization genetic algorithm.

\section{Taguchi design of Experiments}

In order to study the entire process parameter space with a small number of experiments only, Taguchi's method uses a special design of orthogonal arrays ${ }^{34}$. The Taguchi approach is a more effective method than traditional design of experiment methods such as factorial design, which is resource and time consuming. With this method the number of experiments to evaluate the influence of control parameters on certain quality properties or characteristics is markedly reduced compared to a full factorial approach. For example, a process with 8 variables, each with 3 states, would require $3^{8}=6561$ experiments to test all variables (full factorial design). However, using Taguchi's orthogonal arrays, only
18 experiments are necessary, i.e. less than $0.3 \%$ of the original number of experiments. Taguchi recommends the use of the loss function to determine the deviation between the experimental value of the performance characteristic and the desired value. The loss function is further transformed into an $\mathrm{S} / \mathrm{N}$ ratio, which is used to rank the influencing parameters according to their impact on the measured value. After that, the significant parameters can be separated from the parameters which are negligible using ANOVA. This allows a prediction of the optimal manufacturing or process parameters ${ }^{35}$. To verify the predicted optimal testing parameters, a confirmation experiment with these parameters should be employed ${ }^{36,37}$.

In the calculation of the loss function there are three ways of transformation depending on the desired characteristic of the measured value. The characteristic of the desired value can either be the-lower-the-better, the-higher-the-better or the-nominal-the better. The loss function of the "the-nominalthe-better" quality characteristic $\left(y_{k}\right)$ with $\mathrm{m}$ as the mean of the target quality parameter is calculated as shown in Eq. (1) where $L_{i j}$ is the loss function of the $i^{\text {th }}$ performance characteristic in the $\mathrm{j}^{\text {th }}$ experiment.

The loss function of the "the-lower-the-better" and the "the higher- the-better" from the target value of the quality performance characteristic are shown in Eqs. (2) and (3), respectively.

$$
\begin{gathered}
L_{i j}=\frac{1}{n} \sum_{k=1}^{n}\left(y_{i j}-m\right)^{2} \\
L_{i j}=\frac{1}{n} \sum_{k=1}^{n} y_{i j}^{2} \\
L_{i j}=\frac{1}{n} \sum_{k=1}^{n} \frac{1}{y_{i j}{ }^{2}}
\end{gathered}
$$

In the Taguchi method, the $\mathrm{S} / \mathrm{N}$ ratio is used to determine the deviation of the performance characteristic from the desired value. The $\mathrm{S} / \mathrm{N}$ ratio $n_{i j}$ for the $\mathrm{i}^{\text {th }}$ performance characteristic in the $\mathrm{j}^{\text {th }}$ experiment can be calculated using the following equation:

$$
n_{i j}=-10 \log \left(L_{i j}\right)
$$

Regardless of the category of the performance characteristic, a larger $\mathrm{S} / \mathrm{N}$ ratio corresponds to a better-quality performance. Therefore, the optimal level of the process parameters is the level with the highest $\mathrm{S} / \mathrm{N}$ ratio ${ }^{38,39}$.

The selection of control factors is the most important part in the design of experiment. Therefore, many factors are initially included so that the non-significant variables can be identified easily. Factors like heating rate $(a)$, temperature $\left(T_{1}\right)$, time $\left(h_{1}\right)$ largely influence the mechanical behavior of the epoxy matrix ${ }^{19-22}$ and, consequently, of the laminated composite. The impact of these three factors on tensile 
and fracture stresses in glass fabric/epoxy composites is, therefore, studied in this work using an $\mathrm{L}_{25}$ orthogonal array design. The selected levels of the three control factors are listed in Table 1. Since to different targets are included in this study, i.e. tensile and flexural performance, the levels of the temperature factor $\left(T_{1}\right)$ should be both below and above $T_{g}$ temperature, in order to investigate all the curing mechanisms can be achieved $d^{3-5,19-21}$. The levels of the time factor $\left(h_{l}\right)$ and the heating rate factor $(a)$ were selected to be in accordance with both the literature ${ }^{19-21,40}$ and manufacturers' guides for similar epoxy systems.

\section{Experimental Procedure}

\subsection{Materials}

The low-viscosity Araldite GY 783 epoxy resin combined with the low-viscosity, phenol free, modified cycloaliphatic polyamine hardener was used as matrix material for the composite specimens of the present study. The glass transition temperature $(T g)$ was $100^{\circ} \mathrm{C}$ and the gel time for the specific matrix composition at $20^{\circ} \mathrm{C}$ and $65 \%$ relative humidity ( $\mathrm{RH})$, conditioning requirements which were obeyed during the preparation of the composites laminates, was $35 \mathrm{~min}$. Woven E-glass fabric of $282 \mathrm{~g} / \mathrm{m}^{2}$ density was used for matrix reinforcement, as presented in Fig.1. Fig.2 presents an explosive view of the fabrication process together with the E-glass fabric $(\mathrm{P})$ orientations in the composite laminates. The characteristics of the fabric used can be found in Table 2 . Since the warp direction is the enhanced one, see Table 2, it is clear that this is the main weave direction. Therefore, the laminae orientations in the stacking sequence of the composites will be based on the warp direction.

\subsection{Preparation of E-glass fabric/epoxy composites}

Weighed amount of hardener was added into the epoxy resin (monomer) at the manufacturer recommended monomer/ hardener proportion, which was a $100: 50$ by weight ratio, and stirred gently using a laboratory mixer for mechanical

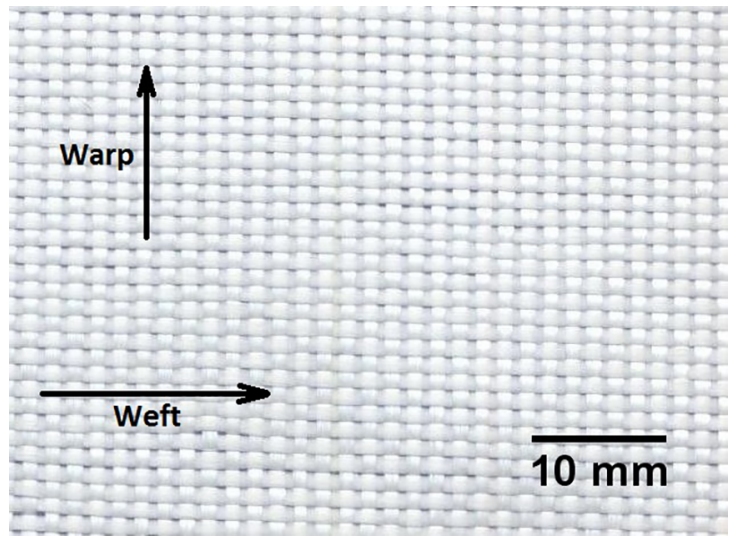

Figure 1. The woven E-glass fabric used in layer orientation $0^{\circ}$.

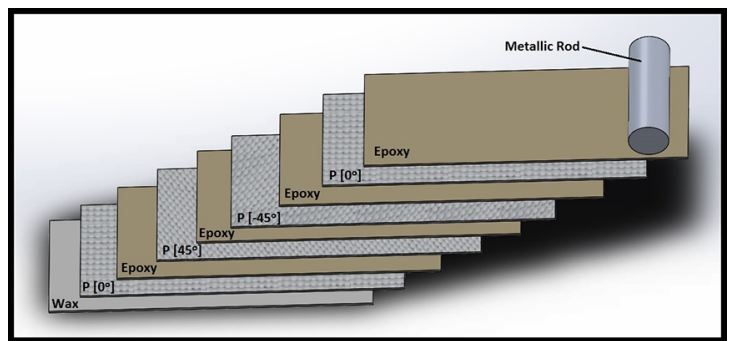

Figure 2. Layer sequence and fabric orientation on the tested $\left[0^{\circ} / 45^{\circ} /-45^{\circ} / 0^{\circ}\right]_{\mathrm{T}}$ laminates.

stirring for a process time of $5 \mathrm{~min}$ at $200 \mathrm{rpm}$. Subsequently, the matrix mixture was coated and hand-rolled on E-glass fabrics in layer sequence under constant stirring. For each hand lay-up procedure, four layers of E-glass fabric were employed in $\left[0^{\circ} / 45^{\circ} /-45^{\circ} / 0^{\circ}\right]_{\mathrm{T}}$ sequence. Before the first layer coating, the surface on which the specimens were produced was covered by release paste wax. The hand layup procedure applied, along with the stacking sequence of the specimens, is presented in Fig. 2 through a 3D model in explosive view mode. The processing temperature for the hand lay-up process applied was $23 \pm 1^{\circ} \mathrm{C}$ (ambient temperature). To achieve a $40 \pm 1 \%$ by volume epoxy proportion in all specimens, both the fabric and the matrix mixture used for

Table 1. Parameters and Design of Experiments (DOE) Levels.

\begin{tabular}{|c|c|c|c|c|c|c|}
\hline \multirow{2}{*}{ Control factor } & \multicolumn{5}{|c|}{ Level } & \multirow{2}{*}{ Units } \\
\hline & I & II & III & IV & $\mathrm{V}$ & \\
\hline Heating Rate $\boldsymbol{a}$ & 1 & 2 & 3 & 4 & 5 & ${ }^{\circ} \mathrm{C} / \mathrm{min}$ \\
\hline Temperature $\boldsymbol{T}_{l}$ & 50 & 80 & 100 & 120 & 140 & ${ }^{\circ} \mathrm{C}$ \\
\hline Time $\boldsymbol{h}_{l}$ & 2 & 4 & 6 & 8 & 10 & $\mathrm{~h}$ \\
\hline
\end{tabular}

Table 2. Characteristics of the glass fabrics used.

\begin{tabular}{lcc}
\hline & Warp & Weft \\
\hline Fiber description & Glass EC11 204 fiber & Glass EC11 204 fiber \\
Thread count (ends/cm) & 8 & 6 \\
Weight distribution $(\%)$ & 57 & 43 \\
\hline
\end{tabular}


coating were weighed before each hand lay-up process and after solidification.

The dimensions of each specimen which underwent 3-point bending tests were $93.6 \times 12.7 \times 1.1 \mathrm{~mm}$, as in accordance with ASTM D790-03 test method. The specimens which underwent tensile test had a total size of $102 \times 6 \times 1.1 \mathrm{~mm}$ according to ASTM D3039/3039M. All specimens were cut at their testing dimensions using a Struers Discotom-2 along with a 40A25 cut-off wheel. To evaluate if tabs were needed on the holding regions of the specimens, the theoretical tab limits were marked on the specimens, as indicated from the aforementioned ASTM standard method. Thus, if the failure occurs between the two theoretical tab limits (theoretical control region) no tabs are needed. As it can be seen in Fig.3, the failure occurred into the theoretical control region and, therefore, no tabs are recommended by the ASTM standard used.

For each experiment number (run number) of the Taguchi design of experiments, see Tables 3 and 4, five specimens were prepared and underwent each test (five specimens for each tensile and five for each flexural test).

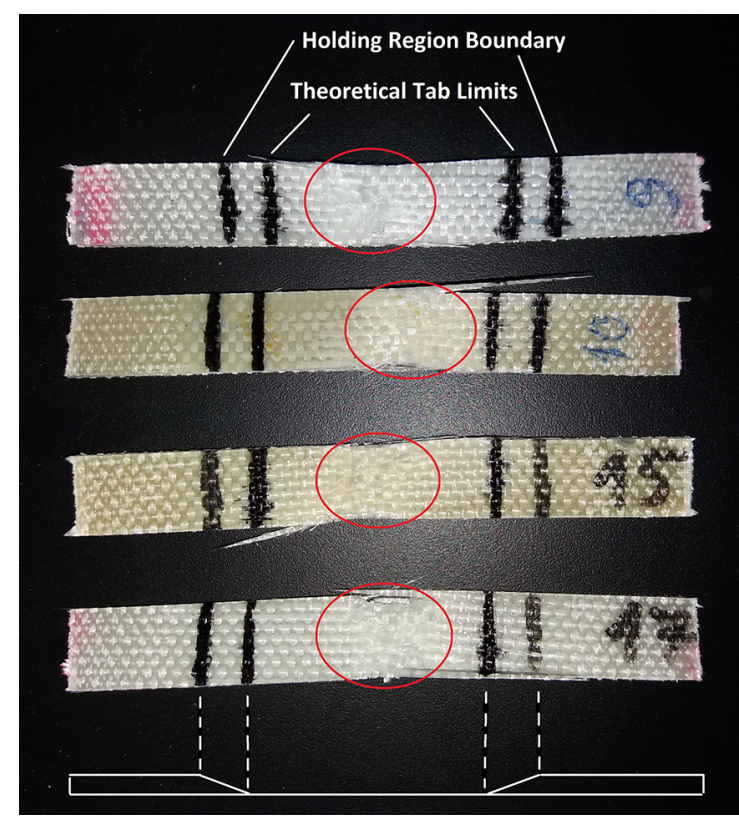

Figure 3. Holding region boundaries and theoretical tab limits for the composite laminates which underwent tensile tests.

Table 3. Taguchi $\mathrm{L}_{25}$ OA response values and $\mathrm{S} / \mathrm{N}$ ratio for Load in Tensile tests.

\begin{tabular}{|c|c|c|c|c|c|}
\hline $\begin{array}{c}\text { Run } \\
\text { No }\end{array}$ & $\begin{array}{c}\text { Heating Rate } \\
\qquad a\end{array}$ & $\begin{array}{c}\text { Temperature } \\
T_{1} \\
\end{array}$ & $\begin{array}{c}\text { Time } \\
h_{1}\end{array}$ & $\begin{array}{c}\text { Load } \\
(\mathrm{N})\end{array}$ & $\begin{array}{c}\text { S/N Ratio } \\
\text { (dB) }\end{array}$ \\
\hline 1 & I & I & I & 2612,00 & 68,3395 \\
\hline 2 & I & II & II & 3690,00 & 71,3405 \\
\hline 3 & I & III & III & 2797,50 & 68,9354 \\
\hline 4 & I & IV & IV & 3397,00 & 70,6219 \\
\hline 5 & I & V & V & 2971,00 & 69,4581 \\
\hline 6 & II & I & II & 2736,75 & 68,7447 \\
\hline 7 & II & II & III & 3059,00 & 69,7116 \\
\hline 8 & II & III & IV & 3643,00 & 71,2292 \\
\hline 9 & II & IV & $\mathrm{V}$ & 3275,00 & 70,3042 \\
\hline 10 & II & V & I & 3122,00 & 69,8887 \\
\hline 11 & III & I & III & 2894,00 & 69,2300 \\
\hline 12 & III & II & IV & 3178,50 & 70,0444 \\
\hline 13 & III & III & $\mathrm{V}$ & 2831,00 & 68,7542 \\
\hline 14 & III & IV & I & 3307,50 & 70,3900 \\
\hline 15 & III & V & II & 3309,00 & 70,3939 \\
\hline 16 & IV & I & IV & 2938,00 & 69,3610 \\
\hline 17 & IV & II & V & 2769,00 & 68,8465 \\
\hline 18 & IV & III & I & 3156,00 & 69,9827 \\
\hline 19 & IV & IV & II & 3862,33 & 71,7370 \\
\hline 20 & IV & V & III & 3629,50 & 71,1969 \\
\hline 21 & V & I & V & 2526,00 & 68,0487 \\
\hline 22 & V & II & I & 2594,50 & 68,2811 \\
\hline 23 & V & III & II & 3409,50 & 70,6538 \\
\hline 24 & V & IV & III & 3277,50 & 70,3109 \\
\hline 25 & V & V & IV & 3542,50 & 70,9862 \\
\hline
\end{tabular}


Table 4. Taguchi $\mathrm{L}_{25} \mathrm{OA}$ response values a nd $\mathrm{S} / \mathrm{N}$ ratio for Stress in Flexural tests.

\begin{tabular}{|c|c|c|c|c|c|}
\hline $\begin{array}{l}\text { Run } \\
\text { No }\end{array}$ & $\begin{array}{l}\text { Heating Rate } \\
a\end{array}$ & $\begin{array}{c}\text { Temperature } \\
T_{1}\end{array}$ & $\begin{array}{c}\text { Time } \\
h_{l}\end{array}$ & $\begin{array}{l}\text { Stress } \\
\text { (MPa) }\end{array}$ & $\begin{array}{l}\text { S/N Ratio } \\
\text { (dB) }\end{array}$ \\
\hline 1 & I & I & I & 143,333 & 42,7872 \\
\hline 2 & I & II & II & 327,333 & 50,2998 \\
\hline 3 & I & III & III & 286,333 & 49,1374 \\
\hline 4 & I & IV & IV & 442,667 & 52,9215 \\
\hline 5 & I & V & V & 299,5 & 49,7259 \\
\hline 6 & II & I & II & 295 & 49,3964 \\
\hline 7 & II & II & III & 346 & 50,7815 \\
\hline 8 & II & III & IV & 369 & 51,3405 \\
\hline 9 & II & IV & V & 420 & 52,465 \\
\hline 10 & II & V & I & 371 & 51,3875 \\
\hline 11 & III & I & III & 307 & 49,7428 \\
\hline 12 & III & II & IV & 362,5 & 51,1862 \\
\hline 13 & III & III & V & 318,5 & 49,9065 \\
\hline 14 & III & IV & I & 349 & 50,8565 \\
\hline 15 & III & V & II & 297 & 49,4551 \\
\hline 16 & IV & I & IV & 277,5 & 48,8653 \\
\hline 17 & IV & II & V & 335,5 & 50,5139 \\
\hline 18 & IV & III & I & 235 & 47,4214 \\
\hline 19 & IV & IV & II & 402,667 & 52,0989 \\
\hline 20 & IV & V & III & 387,5 & 51,7654 \\
\hline 21 & V & I & V & 306,5 & 45,8673 \\
\hline 22 & V & II & I & 149,5 & 43,4928 \\
\hline 23 & V & III & II & 357,5 & 51,0655 \\
\hline 24 & V & IV & III & 377,5 & 51,5383 \\
\hline 25 & V & V & IV & 477,5 & 53,5795 \\
\hline
\end{tabular}

\subsection{Curing of E-glass fabric/epoxy composites}

All specimens left in ambient temperature for 6 hours before the curing conditions of the Taguchi design of experiments, as described in Tables 3 and 4, were applied. Therefore, the complete curing cycle applied is presented in Fig.4, where parameter $a, T_{1}$ and $h_{1}$ represent the heating rate $\left[{ }^{\circ} \mathrm{C} / \mathrm{min}\right]$, the temperature of the first curing step $\left[{ }^{\circ} \mathrm{C}\right]$ and the duration of the first curing step [h], respectively. The selected values for each parameter under study (i.e. the design of experiment levels) can be found in Table 1.

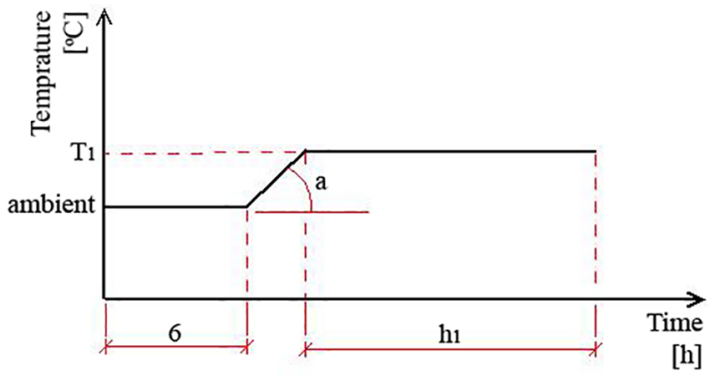

Figure 4. The curing cycle applied together with the parameters of the Taguchi design of the experiments. Ambient temperature is considered equal to $23 \pm 1{ }^{\circ} \mathrm{C}, a$ is the heating rate $\left[{ }^{\circ} \mathrm{C} / \mathrm{min}\right.$ ], $T_{l}$ is the curing temperature $\left[{ }^{\circ} \mathrm{C}\right]$ and $h$ is the curing time $[\mathrm{h}]$.
The curing temperature $\left(T_{\text {cure }}\right)$ can be either higher or lower of the glass transition temperature $\left(T_{g}\right)^{3-5}$. When $T_{\text {cure }}>T_{g}$, the reaction proceeds rapidly at a rate driven by chemical kinetics. When $T_{\text {cure }}=T_{g}$, vitrification takes place (i.e. material solidifies). Finally, when $T_{\text {cure }}<T_{g}$, the reaction rate decelerates and becomes diffusion-controlled. In order to include all the aforementioned mechanisms in the Taguchi design of experiments, apart from the $T_{g}$ temperature, two different temperatures under $T_{g}$ were selected as well as two different temperatures over it, see Table 1.

\subsection{Experimental set-up and tests}

The test machine used for the both tensile and 3-point bending tests was an Instron 4482 of $100 \mathrm{kN}$ capacity. In accordance with the ASTM standard methods used, i.e. D790-03 and D3039/3039M, all tests were performed in a standard laboratory atmosphere $\left(23 \pm 1^{\circ} \mathrm{C}\right.$ and $50 \pm 5 \%$ relative humidity). Test conditioning was kept constant for 6 hours before each test. To meet the test method's span-to-depth specification, the support span was set at $52 \mathrm{~mm}$ for the flexural tests. The recommended from the ASTM methods test speed of $2 \mathrm{~mm} / \mathrm{min}$ was applied on both tensile and 3 -point bending tests. 


\section{Results and Discussion}

\subsection{Taguchi results}

In terms of the $\mathrm{S} / \mathrm{N}$ ratio for stresses and load value, the higher the better. This can be calculated as logarithmic transformation of loss function (Eq. 2). The calculated signal to noise $(\mathrm{S} / \mathrm{N})$ ratio for each experiment is presented in Tables 3 and 4 for tensile and flexural test respectively, along with their experimental results. $\mathrm{S} / \mathrm{N}$ ratio is an important characteristic in order to achieve robustness in Taguchi design of experiment, desired output is known as the signal and variability caused by factors is known as noise.

The main effects plot for the main effect terms in tensile load for factors $a, T_{1}$, and $h_{1}$ are shown in Fig.5. From the main effect plots, it has been observed that the tensile load of the composite increases for heating rate values ranging from $1^{\circ} \mathrm{C} / \mathrm{min}$ to $2^{\circ} \mathrm{C} / \mathrm{min}$ and from $3{ }^{\circ} \mathrm{C} / \mathrm{min}$ to $4{ }^{\circ} \mathrm{C} / \mathrm{min}$ and decreases with faster heating. The curing temperature affects the tensile load increase of the composite material as well. Specifically, while temperature is ranging from $50^{\circ} \mathrm{C}$ to $80^{\circ} \mathrm{C}$ an increase in load occurred. Subsequently, from $80{ }^{\circ} \mathrm{C}$ to $100^{\circ} \mathrm{C}$ the load remains constant and from $100{ }^{\circ} \mathrm{C}$ up to $120^{\circ} \mathrm{C}$ it increases. Further increase in temperature leads to an opposite outcome, showing downgrading of mechanical properties due to thermal decomposition of long chains of the epoxy matrix. With increased temperature, free radicals and developing polymer chains become more fluid as a consequence of decreased viscosity and they react to a greater extent. This results in a more complete polymerization reaction and consequently greater crosslinking ${ }^{41}$. The increase in the degree of polymerization of composites may lead to improved mechanical properties and increased wear resistance ${ }^{42}$. Therefore, it is expected that by increasing the process temperature the performance of the produced composite may be consequently increased as well. It is known that while the temperature increases, the thermal expansion coefficient of epoxy/fiberglass composites is being increased as well ${ }^{43}$. However, it increases with a different rate of change for low and for high temperature values. Specifically, for low temperature values the rate of change is quite low and while increasing the temperature this rate takes considerably greater values. Due to the high values of thermal expansion coefficient for temperatures greater than $120^{\circ} \mathrm{C}$, voids may be formed on the epoxy/ fiberglass interfaces, leading in this manner to a consequent performance drop ${ }^{44}$. The curing time increase affects the increase of the tensile load of the composite material while factor $h_{1}$ is ranging from 2 to 4 hours. From 4 to 6 hours the tensile load decreases. From 6 to 8 hours the load increases and for greater values of $h_{1}$ the load decreases. From the main effect plots of Fig.6, it can be observed that the flexural strength of the composite responses similarly with the tensile load while changing the heating rate value. The temperature increase affects the flexural strength of the composite in the same manner as it affects the tensile load, as well. The $h_{1}$ factor, which represents the curing duration, has a positive effect in terms of increasing the flexural strength of the composite. For $h_{1}$ values up to 8 hours a rise of load can be observed and with further increase of $h_{1}$ factor the flexural strength decreases. In general, an initial performance increase can be observed for both tensile and flexural tests while the curing time increases. Subsequently, the performance shows a decreasing trend. For short curing times, it is known that a curing time increase leads to a subsequent strength increase ${ }^{45}$. The curing cycle had a significant effect on both the tensile and flexural performance of the composites. It is known that the curing cycle affects the polymer chains of the matrix ${ }^{46-49}$ as well as the quality of the fibril/epoxy interface ${ }^{44}$. Due to the different thermal expansion coefficient of the involved components, i.e. fibrils and epoxy matrix, while a composite laminate undergoes thermal cycles during curing, voids may be formed on the fibril/epoxy interfaces leading to an interface interruption ${ }^{44}$.

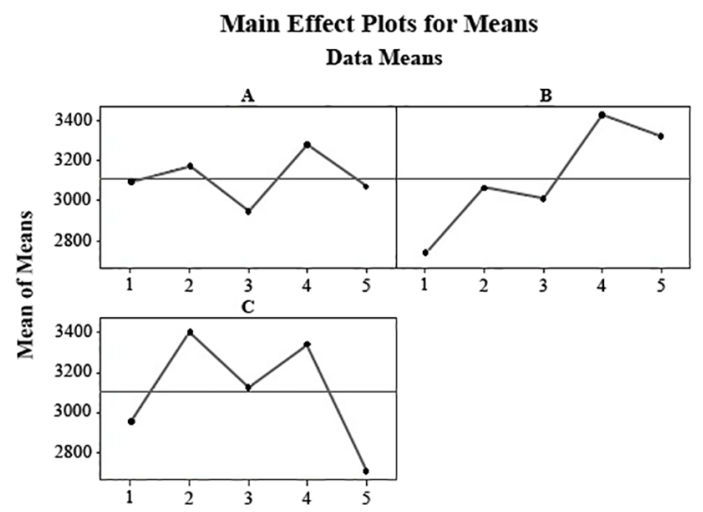

Figure 5. Main effect plots for tensile load for $a$ (heating rate), $T_{1}$ (temperature) and $h_{l}$ (time) factors.

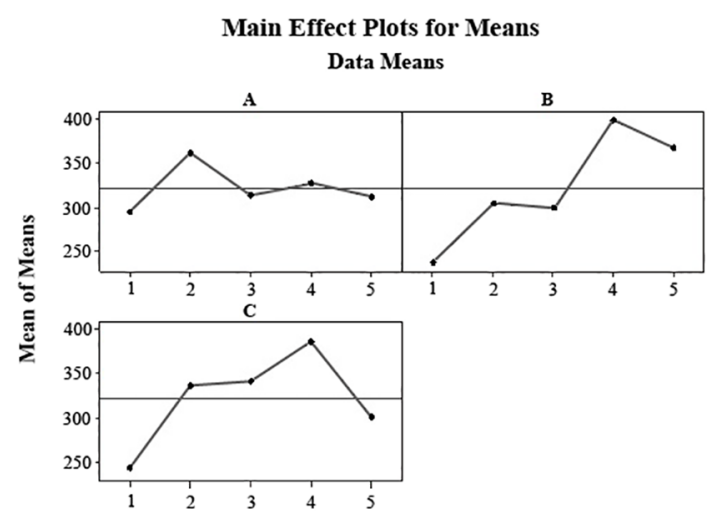

Figure 6. Main effect plots for flexural strength for $a$ (heating rate), $T_{l}$ (temperature) and $h_{l}$ (time) factors. 


\subsection{Analysis of Variance}

Analysis of variance (ANOVA) is a statistical tool which examines the hypothesis that the means of two or more populations are equal. It evaluates the significance of one or more factors by comparing the response variable means at the different factor levels. It was observed that the significant factor for tensile and flexural strength was temperature and time at $95 \%$ confidence level, see Tables 5 and 6 . In order to evaluate the analysis, conformation tests were performed (Tables 7 and 8 ) by comparing actual values and optimal ones. The optimal values can be predicted using Eq. $(5)^{50}$.

$$
n_{\text {opt }}=n_{m}+\sum_{i=1}^{q}\left(n_{i}-n_{m}\right)
$$

where: $\eta_{m}$ is the total mean of the response under consideration (tensile load and flexural strength, respectively); $\eta_{i}$ is the mean response value at the optimum level and $q$ is the number of the curing process control factors that significantly affect the response of the composites after curing.

\subsection{Poisson Regression Analysis with Backward Elimination}

Regression analysis is a statistical process for approximating the relationships between variables. It is a method for modelling different variables. It helps to understand how the dependent variable deviates when any one of the independent variables is changed ${ }^{51}$. Poisson regression is a regression method, which employees a logarithmic transformation that compensates for skewness, prevents a negative predicted value, and also includes the proportionality between variance and the mean ${ }^{52}$.

Therefore, if $Y$ has a Poisson distribution, then a loglinear model can be constructed as

$$
\ln \hat{Y}=\alpha+\beta_{1} X_{1}+\beta_{2} X_{2}+\ldots+\beta_{k} X_{k}
$$

The difficulty of the above form is that the prediction is in terms of log counts. However, in practice actual counts are needed. To handle this difficulty, both sides have to be exponiated.

$$
e^{\ln \hat{Y}}=e^{\left(\alpha+\beta_{1} X_{1}+\beta_{2} X_{2}+\cdots+\beta_{k} X_{k}\right)}
$$

or equally

$$
\hat{Y}=e^{\left(\alpha+\beta_{1} X_{1}+\beta_{2} X_{2}+\cdots+\beta_{k} X_{k}\right)}
$$

In this form, the predicted value of $Y$ is in counts.

The backward elimination applied to all the variants included in the regression. The effect of removing a variable on residual mean square $\left(M S_{\text {res }}\right)$ was assessed for each variable, and the variable with the least effect on increasing $M S_{\text {res }}$ was removed if it did not increase the $F$ ratio for removal, Fout. Fout was set at 4 . The process continued until removal caused a significant change in $M S_{\text {res }}$, when that variant was left in and no further removals were done.

Poisson regression analysis, together with backward elimination, was carried out for tensile load and flexural strength taking all factors $\left(a, T_{l}, h_{l}\right)$ as independent variables. In the case of flexural strength regression model, only the significant factors $\left(T_{1}, h_{1}\right)$ were kept, since the heating rate factor $(a)$ was eliminated by the backward elimination process. Normal probability of regression equation was also plotted in Figs. 7 and 8 for tensile load and flexural strength respectively. The regression coefficients of tensile load and flexural stress values are provided in Tables 9 and 10 respectively.

$$
\text { Tensile } \operatorname{Load}=e^{Y_{1}^{\prime}}
$$

where

$Y_{1}^{\prime}=-0.3-8.8 \times a+0.524 \times T_{1}-0.83 \times h_{1}+0.784 \times a^{2}$ $-0.002901 \times T_{1}^{2}+1.547 \times h^{2}+5.31 \times a \times h_{1}-0.1979 \times T_{1} \times$ $h_{1}+0.000003 \times T_{1}^{3}-0.285 \times h_{1}{ }^{3}-0.3327 \times a \times h^{2}+0.00099$ $\times T_{1}^{2} \times h_{1}+0.01975 \times T_{1} \times h^{2}+0.0153 \times h_{1}{ }^{4}+0.03159 \times$ $a^{2} \times h^{2}+0.126 \times a \times h_{1}{ }^{3}-0.000001 \times T_{1}^{3} \times h_{1}-0.000064 \times$ $T_{1}^{2} \times h^{2}-0.000481 \times T^{1} \times h^{3}-0.00573 \times a \times h^{4}$

$$
\text { Flexural Strength }=e^{Y^{\prime}}
$$

where

$Y_{2}^{\prime}=4.6336+0.009461 \times T_{1}+0.1188 \times h^{1}-0.000792$ $\times T_{1} \times h_{1}$

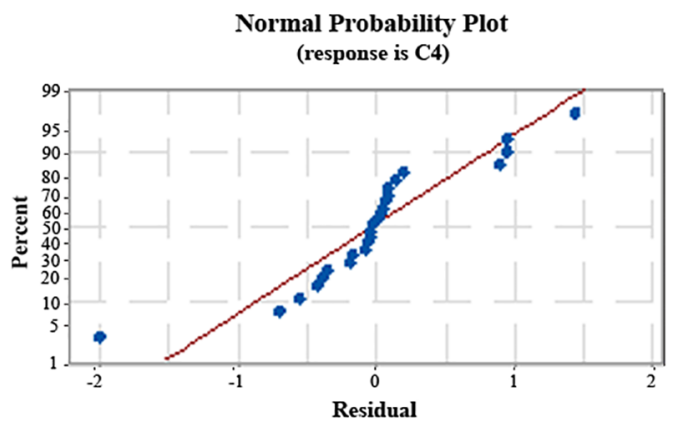

Figure 7. Normal probability of regression equation for tensile load

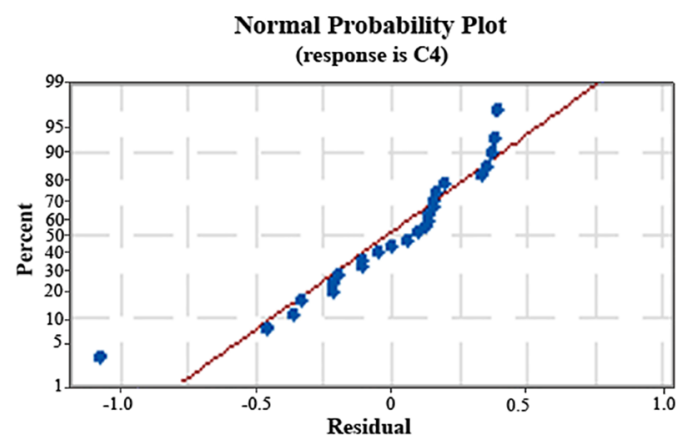

Figure 8. Normal probability of regression equation for flexural strength. 
Table 5. ANOVA for Tensile load value, without interaction, $\mathrm{F}_{0,05,4,12=3,26 \text {. }}$.

\begin{tabular}{ccccccc}
\hline Source & $\mathbf{d F}$ & Sum of squares & Mean square & F-value & P value & C (\%) \\
\hline$a$ & 4 & 293004 & 73251 & 0,80 & 0,367 & 6,62 \\
$T_{l}$ & 4 & 1447822 & 361955 & $3,96^{*}$ & $0,003^{*}$ & 32,71 \\
$h_{l}$ & 4 & 1588652 & 397163 & $4,34 *$ & $0,010^{*}$ & 35,89 \\
Error & 12 & 1097301 & 91442 & & & \\
Total & 24 & 4426778 & & & & \\
\hline
\end{tabular}

*Significant at $95 \%$ confidence level.

Table 6. ANOVA for Flexural stress value, without interaction, $F_{0,05,4,12=3,26}$,

\begin{tabular}{ccccccc}
\hline Source & $\mathbf{d F}$ & Sum of squares & Mean square & F-value & P value & C (\%) \\
\hline$a$ & 4 & 12361 & 3090 & 1,18 & 0,367 & 6,92 \\
$T_{l}$ & 4 & 78612 & 19653 & $7,53^{*}$ & $0,003^{*}$ & 44,02 \\
$h_{l}$ & 4 & 56284 & 14071 & $5,39 *$ & $0,010^{*}$ & 31,52 \\
Error & 12 & 31335 & 2611 & & \\
Total & 24 & 178591 & & & & \\
\hline
\end{tabular}

*Significant at $95 \%$ confidence level.

Table 7. Confirmation table for tensile load.

\begin{tabular}{|c|c|c|}
\hline \multirow[t]{3}{*}{ Parameter } & \multicolumn{2}{|c|}{ Optimal Parameter } \\
\hline & \multicolumn{2}{|c|}{$a=4^{\circ} \mathrm{C} / \mathrm{min}, T_{l}=120^{\circ} \mathrm{C}, h_{l}=4 \mathrm{~h}$} \\
\hline & Experimental & Predicted \\
\hline Load $(\mathrm{N})$ & 3862,33 & 3878,10 \\
\hline Error \% & & \\
\hline
\end{tabular}

Table 8. Confirmation table for flexural strenth.

\begin{tabular}{ccc}
\hline Parameter & \multicolumn{2}{c}{ Optimal Parameter } \\
\hline & \multicolumn{2}{c}{$a=2{ }^{\circ} \mathrm{C} / \mathrm{min}, T_{l}=120^{\circ} \mathrm{C}, h_{l}=8 \mathrm{~h}$} \\
\cline { 2 - 3 } & Experimental & Predicted \\
\hline $\begin{array}{c}\text { Flexural Stress (N) } \\
\text { Error \% }\end{array}$ & 498,70 & 501,93 \\
\hline
\end{tabular}

Taking this data into consideration it is possible to formulate an equation that allows for the prediction of the mechanical behavior of the composite by altering the temperature and the curing time. Figs. 9 and 10 present a comparison between the theoretical model, see Eqs. (9) and (10), and the experimental results for both tensile and flexural tests. It can be easily observed that the experimental and theoretical results always show a perfect correlation. Therefore, the equations of the theoretical model above are a useful tool to accurately predict both the tensile $\left(R^{2}=97.05 \%\right)$ and flexural $\left(R^{2}=98.11 \%\right)$ response of the cured composites.

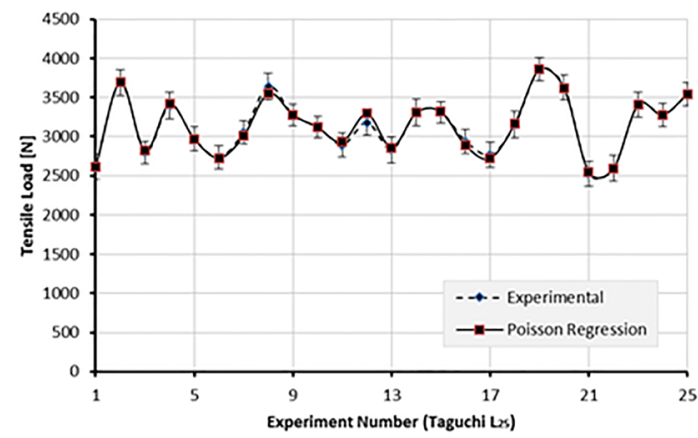

Figure 9. Comparison between the experimental results and the theoretical values of tensile load.

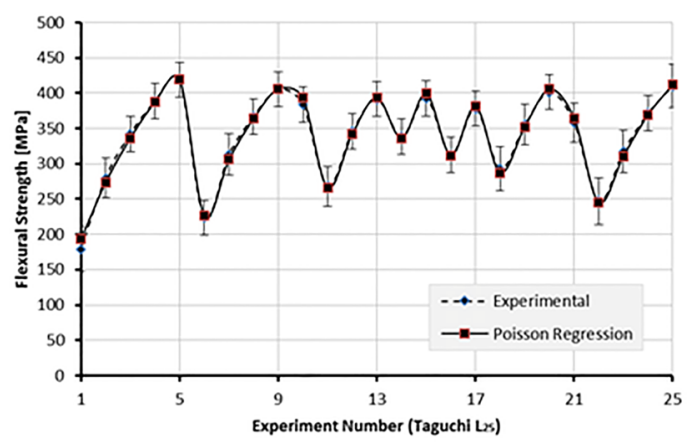

Figure 10. Comparison between the experimental results and the theoretical values of flexural strength.

\section{4 Process optimization using a genetic algorithm}

The aim of the optimization procedure is to determine the optimal values of the curing parameters $\left(a, T_{l}, h_{l}\right)$ that contribute to the maximum values for both criteria; Tensile Load and Flexural Strength. The solution of the aforementioned task lies on the multi-objective optimization concept. The Poisson regression models for both criteria, i.e. Eqs.(9) and (10), were converted into a MATLAB ${ }^{\circledR}$ function for maximizing Tensile Load and Flexural Strength. Therefore, the two-fold function of eq. (11) was created. 
Table 9. Regression coefficients of tensile model with all factors.

\begin{tabular}{|c|c|c|c|c|c|c|}
\hline Term & Coef & SE Coef & \multicolumn{2}{|c|}{$95 \%$ CI } & Z-Value & P-Value \\
\hline Constant & -0.30 & 1.33 & ( - -2.90; & 2.31) & -0.22 & 0.824 \\
\hline $\mathrm{a}$ & -8.80 & 2.15 & ( -13.02; & $-4.58)$ & -4.09 & 0.000 \\
\hline $\mathrm{T}_{1}$ & 0.524 & 0.131 & ( 0.268 & $0.781)$ & 4.01 & 0.000 \\
\hline $\mathrm{h}_{1}$ & -0.83 & 1.12 & ( -3.03; & 1.37) & -0.74 & 0.461 \\
\hline$a^{2}$ & 0.784 & 0.167 & ( 0.457 & 1.111) & 4.70 & 0.000 \\
\hline $\mathrm{T}_{1}^{2}$ & -0.002901 & 0.000848 & $(-0.004563 ;$ & $-0.001239)$ & -3.42 & 0.001 \\
\hline $\mathrm{h}_{1}{ }^{2}$ & 1.547 & 0.672 & ( 0.230 & $2.863)$ & 2.30 & 0.021 \\
\hline$a * h_{1}$ & 5.31 & 1.45 & ( 2.47; & $8.15)$ & 3.67 & 0.000 \\
\hline $\mathrm{T}_{1} * \mathrm{~h}_{1}$ & -0.1979 & 0.0484 & $(-0.2928$ & $-0.1030)$ & -4.09 & 0.000 \\
\hline $\mathrm{T}_{1}^{3}$ & 0.000003 & 0.000002 & $(-0.000000$ & $0.000006)$ & 1.94 & 0.053 \\
\hline$h_{1}{ }^{3}$ & -0.285 & 0.109 & ( - -0.498; & $-0.073)$ & -2.63 & 0.009 \\
\hline$a^{2 *} h_{1}$ & -0.3327 & 0.0728 & ( - 0.4754 & $-0.1900)$ & -4.57 & 0.000 \\
\hline $\mathrm{a}^{*} \mathrm{~h}_{1}{ }^{2}$ & -1.177 & 0.357 & ( -1.876; & $-0.479)$ & -3.30 & 0.001 \\
\hline $\mathrm{T}_{1}^{2 *} \mathrm{~h}_{1}$ & 0.000990 & 0.000248 & ( 0.000504; & $0.001477)$ & 3.99 & 0.000 \\
\hline $\mathrm{T}_{1} * \mathrm{~h}_{1}^{2}$ & 0.01975 & 0.00507 & ( 0.00981; & 0.02969) & 3.89 & 0.000 \\
\hline $\mathrm{h}_{1}{ }^{4}$ & 0.01530 & 0.00550 & ( 0.00452 & $0.02607)$ & 2.78 & 0.005 \\
\hline$a * a * h_{1}{ }^{2}$ & 0.03159 & 0.00741 & ( 0.01707 & $0.04612)$ & 4.26 & 0.000 \\
\hline $\mathrm{a}^{*} \mathrm{~h}_{1}{ }^{3}$ & 0.1260 & 0.0403 & ( 0.0471 & $0.2049)$ & 3.13 & 0.002 \\
\hline $\mathrm{T}_{1}^{3 * \mathrm{~h}_{1}}$ & -0.000001 & 0.000000 & $(-0.000002$ & $-0.000000)$ & -3.43 & 0.001 \\
\hline $\mathrm{T}_{1}^{2 *} \mathrm{~h}_{1}^{2}$ & -0.000064 & 0.000017 & $(-0.000097$ & $-0.000031)$ & -3.84 & 0.000 \\
\hline $\mathrm{T}_{1} * \mathrm{~h}_{1}{ }^{3}$ & -0.000481 & 0.000128 & $(-0.000731$ & $-0.000231)$ & -3.77 & 0.000 \\
\hline $\mathrm{a}^{*} \mathrm{~h}_{1}{ }^{4}$ & -0.00573 & 0.00183 & $(-0.00932$ & $-0.00214)$ & -3.13 & 0.002 \\
\hline
\end{tabular}

Table 10. Regression coefficients of flexural model with significant factors.

\begin{tabular}{|c|c|c|c|c|c|c|}
\hline Term & Coef & SE Coef & \multicolumn{2}{|c|}{$95 \%$ CI } & Z-Value & P-Value \\
\hline Constant & 4.6336 & 0.0952 & ( 4.4469; & 4.8202) & 48.66 & 0.000 \\
\hline $\mathrm{T}_{1}$ & 0.009461 & 0.000879 & ( 0.007739; & $0.011183)$ & 10.77 & 0.000 \\
\hline $\mathrm{h}_{1}$ & 0.1188 & 0.0135 & ( ) 0.0924; & $0.1453)$ & 8.80 & 0.000 \\
\hline $\mathrm{T}_{1} * \mathrm{~h}_{1}$ & -0.000792 & 0.000126 & $(-0.001039$ & $-0.000545)$ & -6.28 & 0.000 \\
\hline
\end{tabular}

$\max f\left(a, T_{1}, h_{1}\right)=\left\{\begin{aligned} \max \text { Tensile Load } & =\min (1 / \text { Tensile Load })=\min \left(1 / e^{r_{1}}\right) \\ \max \text { Flexural Strength } & =\min (1 / \text { Flexural Strength })=\min \left(1 / e^{y}\right.\end{aligned}\right.$

where

$Y_{1}^{\prime}=-0.3-8.8 \times a+0.524 \times T_{1}-0.83 \times h_{1}+0.784 \times a^{2}$ $-0.002901 \times T_{1}^{2}+1.547 \times h^{2}+5.31 \times a \times h_{1}-0.1979 \times T_{1} \times$ $h_{1}+0.000003 \times T_{1}^{3}-0.285 \times h_{1}^{3}-0.3327 \times a \times h^{2}+0.00099$ $\times T_{1}^{2} \times h_{1}+0.01975 \times T_{1} \times h^{2}+0.0153 \times h_{1}^{4}+0.03159 \times$ $a^{2} \times h^{2}+0.126 \times a \times h_{1}^{3}-0.000001 \times T_{1}^{3} \times h_{1}-0.000064 \times$ $T_{1}^{2} \times h^{2}-0.000481 \times T^{1} \times h^{3}-0.00573 \times a \times h^{4}$

and

$Y_{2}^{\prime}=4.6336+0.009461 \times T_{1}+0.1188 \times h^{1}-0.000792$ $\times T_{1} \times h_{1}$

Eq. (11) was the fitness function for the multi-objective optimization GA of MATLAB $\AA$ optimization toolbox. For the optimization process a population size of 45 individuals
$(15 *$ number of variables) was specified to evolve for 500 generations with 0.8 probability single point crossover and a constraint dependent mutation function. The algorithmic parameter values were selected as recommended by the optimization toolbox employed, i.e. the migration interval was set to 20; migration fraction was set to 0.2 and Pareto fraction was set to 0.35 .

The Pareto-optimal solutions obtained together with their corresponding performance values are summarized in Table 11. The average distance between individuals (candidate solutions) referring to the objective values is depicted in Fig.11. As can be seen in Table 11, the minimum individual distance was obtained for solutions 1 and 2 . Therefore, the respective Pareto-optimal fonts indicate that the curing process is optimum, as per the maximization of both tensile and flexural performance, for $a=1\left({ }^{\circ} \mathrm{C} / \mathrm{min}\right)$, $T_{1}=85\left({ }^{\circ} \mathrm{C}\right)$ and $h_{1}=10(\mathrm{~h})$. 
Table 11. Pareto font-function values and optimal curing parameters.

\begin{tabular}{|c|c|c|c|c|}
\hline Solution no. & $a\left({ }^{\circ} \mathrm{C} / \mathrm{min}\right)$ & $T_{1}\left({ }^{\circ} \mathrm{C}\right)$ & $h_{1}(\mathrm{~h})$ & Pareto distance \\
\hline 1 & 1.001841317 & 139.9999999 & 9.999999959 & 1.6914 \\
\hline 2 & 1.000105286 & 85.51085564 & 9.997251776 & 1.4935 \\
\hline 3 & 1.001847642 & 139.4348674 & 9.99881099 & 1.6890 \\
\hline 4 & 1.001838635 & 135.9951147 & 9.999994125 & 1.6747 \\
\hline 5 & 1.000105286 & 85.51085564 & 9.997251776 & 1.4935 \\
\hline 6 & 1.001731003 & 137.6706621 & 9.999573415 & 1.6816 \\
\hline 7 & 1.00182876 & 135.1332839 & 9.999991494 & 1.6711 \\
\hline 8 & 1.001841317 & 139.9999999 & 9.999999959 & 1.6914 \\
\hline 9 & 1.008023956 & 136.3610771 & 9.990931862 & 1.6788 \\
\hline 10 & 1.014562832 & 126.9283418 & 9.986363612 & 1.6438 \\
\hline 11 & 1.001839871 & 138.3768794 & 9.999494526 & 1.6846 \\
\hline 12 & 1.079739416 & 118.477614 & 9.971796304 & 1.6464 \\
\hline 13 & 1.001841216 & 137.2358606 & 9.999992492 & 1.6798 \\
\hline 14 & 1.00264489 & 133.0118608 & 9.979005419 & 1.6616 \\
\hline 15 & 1.001839235 & 139.0998201 & 9.999996542 & 1.6876 \\
\hline 16 & 1.008728622 & 134.1460715 & 9.999806411 & 1.6706 \\
\hline
\end{tabular}

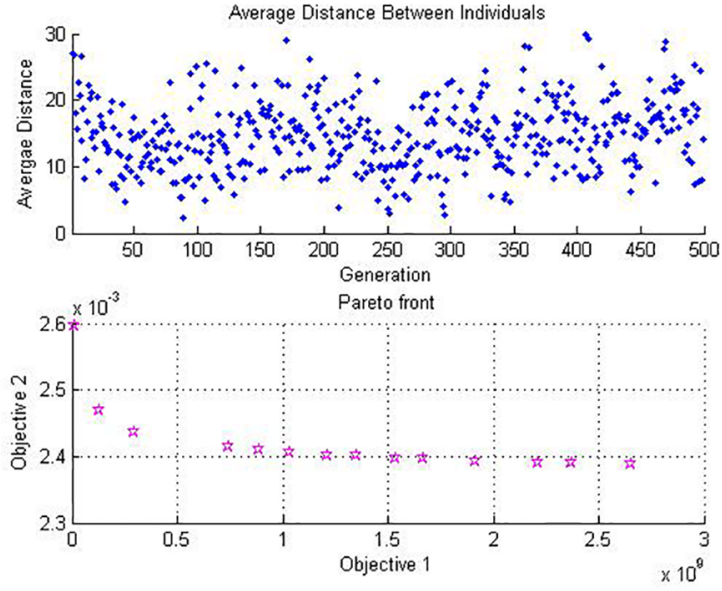

Figure 11. Average distance between individuals per generation and Pareto front.

\section{Conclusions}

Woven E-glass fabric/epoxy laminated composites were produced and underwent tensile and flexural testing according to a $\mathrm{L}_{25}$ Taguchi design of experiments. Based on the experimental results as well as the subsequent statistical analysis and genetic algorithm the following remarks may be drawn:

(a) The significant parameters for both tensile and flexural strength are temperature $\left(T_{1}\right)$ and duration $\left(h_{1}\right)$, at a $95 \%$ confidence level. Therefore, for slow temperature increase values, i.e. $1-5{ }^{\circ} \mathrm{C} / \mathrm{min}$, the effect of the heating rate $a$ on the performance of the cured laminated composite is not considerable.

(b) The estimation of the curing parameters for optimum tensile and flexural performance can be achieved with an error considerably lower than $1 \%$. More specifically, the error of the calculated optimum tensile performance was $0.41 \%$ and of the flexural performance $0.65 \%$. (c) The optimum performance was obtained for temperature $T_{l}$ values greater than the glass transition temperature $T_{g}$. It is known that when $T_{\text {cure }}>T_{g}$, the reaction proceeds rapidly at a rate driven by chemical kinetics and when $T_{\text {cure }}<T_{g}$, the reaction rate decelerates and becomes diffusion-controlled. Therefore, it is obvious that both tensile and flexural performance of the epoxy matrix laminated composites is mainly controlled by the chemical kinetics.

(d) Poisson Regression Analysis, together with backward elimination, led to a theoretical model, the correlation of which with the experimental results was almost perfect. Therefore, the Poisson regression theoretical model can accurately predict both the tensile and flexural response of the cured composites.

(e) The optimum curing process, as regards the maximization of both tensile and flexural performance, can be obtained for temperature $T_{1}$ lower than the glass transition temperature $T_{g}$ (diffusion-controlled reaction). Additionally, even if the heating rate $a$ is not a significant factor, the optimum curing process requires a low $a$ value, equal to $1^{\circ} \mathrm{C} / \mathrm{min}$.

\section{References}

1. Gao L, Zhang Q, Guo J, Li H, Wu J, Yang X, et al. Effects of the amine/epoxy stoichiometry on the curing behavior and glass transition temperature of MWCNTs-NH2/epoxy nanocomposites. Thermochimica Acta. 2016;639:98-107.

2. Fu Y, Zhong, WH. Cure kinetics behavior of a functionalized graphitic nanofiber modified epoxy resin. Thermochimica Acta. 2011;516(1-2):58-63.

3. Moussa O, Vassilopoulos AP, Keller T. Effects of low-temperature curing on physical behavior of cold-curing epoxy adhesives in bridge construction. International Journal of Adhesion and Adhesives. 2012;32:15-22. 
4. Ellis B. Chemistry and Technology of Epoxy Resins. Dordrecht: Springer; 1993.

5. Wisanrakkit G, Gillham JK. Glass transition temperature (Tg) as an index of chemical conversion for high-Tg amine/epoxy system: Chemical and diffusion controlled reaction kinetics. Journal of Applied Polymer Science. 1990;41(11-12):2885-2929.

6. Maljaee H, Ghiassi B, Lourenço PB. Effect of synergistic environmental conditions on thermal properties of a cold curing epoxy resin. Composites Part B: Engineering. 2017;113:152-163.

7. Kwak M, Robinson P, Bismarck A, Wise R. Microwave curing of carbon-epoxy composites: Penetration depth and material characterisation. Composites Part A: Applied Science and Manufacturing. 2015;75:18-27.

8. Johnston K, Pavuluri SK, Leonard MT, Desmulliez MPY, Arrighi V. Microwave and thermal curing of an epoxy resin for microelectronic applications. Thermochimica Acta. 2015;616:100-109.

9. De Vergara UL, Sarrionandia M, Gondra K, Aurrekoetxea J. Polymerization and curing kinetics of furan resins under conventional and microwave heating. Thermochimica Acta. 2014;581:92-99.

10. Mijovic J, Fishbain A, Wijaya J. Mechanistic modeling of epoxy amine kinetics. 2. Comparison of kinetics in thermal and microwave fields. Macromolecules. 1992;25(2):986-989.

11. Barbosa AQ, da Silva LFM, Abenojar J, Figueiredo M, Öchsner A. Toughness of a brittle epoxy resin reinforced with micro cork particles: Effect of size, amount and surface treatment. Composites Part B: Engineering. 2017;114:299-310.

12. Thipprakmas S. Application of Taguchi technique to investigation of geometry and position of V-ring indenter in fine-blanking process. Materials and Design (1980-2015). 2010;31(5):2496-2500.

13. Parida AK, Routara BC, Bhuyan RK. Surface roughness model and parametric optimization in machining of GFRP composite: Taguchi and Response surface methodology approach. MaterialsToday: Proceedings. 2015;2(4-5):3065-3074.

14. Rout AK, Satapathy A. Study on mechanical and tribo-performance of rice-husk filled glass-epoxy hybrid composites. Materials and Design. 2012;41:131-141.

15. Kishore RA, Tiwari R, Dvivedi A, Singh I. Taguchi analysis of the residual tensile strength after drilling in glass fiber reinforced epoxy composites. Materials and Design. 2009;30(6):21862190.

16. Gaitonde VN, Karnik SR, Rubio JC, Correia AE, Abrão AM, Davim JP. Analysis of parametric influence on delamination in high-speed drilling of carbon fiber reinforced plastic composites. Journal of Materials Processing Technology. 2008;203(13):431-438

17. Tsao CC, Hocheng H. Taguchi analysis of delamination associated with various drill bits in drilling of composite material. International Journal of Machine Tools and Manufacture. 2004;44(10):1085-1090.

18. Davim JP, Reis P. Drilling carbon fiber reinforced plastics manufactured by autoclave - experimental and statistical study. Materials and Design. 2003;24(5):315-324.
19. Davies LW, Day RJ, Bond D, Nesbitt A, Ellis J, Gardon E. Effect of cure cycle heat transfer rates on the physical and mechanical properties of an epoxy matrix composite. Composites Science and Technology. 2007;67(9):1892-1899.

20. Kumar DS, Shukla MJ, Mahato KK, Rathore DK, Prusty RK, Ray BC. Effect of post-curing on thermal and mechanical behavior of GFRP composites. IOP Conference Series: Materials Science and Engineering. 2015;75:012012. DOI: 10.1088/1757-899X/75/1/012012

21. Aruniit A, Kers J, Krumme A, Poltimäe T, Tall K. Preliminary Study of the Influence of Post Curing Parameters to the Particle Reinforced Composite\&apos;s Mechanical and Physical Properties. Materials Science. 2012;18(3):256-261.

22. Sultania M, Rai JSP, Srivastava D. Process modeling, optimization and analysis of esterification reaction of cashew nut shell liquid (CNSL)-derived epoxy resin using response surface methodology. Journal of Hazardous Materials. 2011;185(2-3):1198-1204.

23. Guo H, Wang X, Gao Z. Uncertain linear regression model and its application. Journal of Intelligent Manufacturing. 2017;28(3):559-564. DOI: 10.1007/s10845-014-1022-1024

24. Tangjitsitcharoen S, Thesniyom P, Ratanakuakangwan S. Prediction of surface roughness in ball-end milling process by utilizing dynamic cutting force ratio. Journal of Intelligent Manufacturing. 2017;28(1):13-21. DOI: 10.1007/s10845-0140958-8

25. Luangpaiboon P, Boonhao S, Montemanni R. Steepest ant sense algorithm for parameter optimization of multi-response processes based on taguchi design. Journal of Intelligent Manufacturing. 2016. DOI: $10.1007 / \mathrm{s} 10845-016-1257-3$

26. Sharma N, Kumar K, Raj T, Kumar V. Porosity exploration of SMA by Taguchi, regression analysis and genetic programming. Journal of Intelligent Manufacturing . 2016. DOI: 10.1007/ s10845-016-1236-8

27. Li C, Li L, Tang Y, Zhu Y, Li L. A comprehensive approach to parameters optimization of energy-aware CNC milling. Journal of Intelligent Manufacturing. 2016. DOI: 10.1007/ s10845-016-1233-y

28. Li H, Wang Y, Zhao P, Zhang X, Zhou P. Cutting tool operational reliability prediction based on acoustic emission and logistic regression model. Journal of Intelligent Manufacturing. 2015;26(5):923-931. DOI: 10.1007/s10845-014-0941-4

29. Jurkovic Z, Cukor G, Brezocnik M, Brajkovic T. A comparison of machine learning methods for cutting parameters prediction in high speed turning process. Journal of Intelligent Manufacturing. 2016. DOI: $10.1007 / \mathrm{s} 10845-016-1206-1$

30. Ferdosian F, Zhang Y, Yuan Z, Anderson M, Xu C. Curing kinetics and mechanical properties of bio-based epoxy composites comprising lignin-based epoxy resins. European Polymer Journal. 2016;82:153-165.

31. Joosten MW, Agius S, Hilditch T, Wang C. Effect of residual stress on the matrix fatigue cracking of rapidly cured epoxy/ anhydride composites. Composites Part A: Applied Science and Manufacturing. 2017;101:521-528. 
32. Seretis GV, Kouzilos G, Manolakos DE, Provatidis CG. On the graphene nanoplatelets reinforcement of hand lay-up glass fabric/epoxy laminated composites. Composites Part B: Engineering. 2017;118:26-32.

33. Omrani E, Barari B, Maghadam AD, Rohatgi PK, Pillai KM. Mechanical and tribological properties of self-lubricating bio-based carbon-fabric epoxy composites made using liquid composite molding. Tribology International. 2015;92:222-232.

34. Montgomery DC. Design and Analysis of Experiments. New York: John Wiley \& Sons; 2001.

35. Rashmi, Renukappa NM, Suresha B, Devarajaiah RM, Shivakumar KN. Dry sliding wear behaviour of organo-modified montmorillonite filled epoxy nanocomposites using Taguchi's techniques. Materials \& Design. 2011;32(8-9):4528-4536.

36. Naghibi S, Sani MAF, Hosseini HRM. Application of the statistical Taguchi method to optimize $\mathrm{TiO}_{2}$ nanoparticles synthesis by the hydrothermal assisted sol-gel technique. Ceramics International. 2014;40(3):4193-4201.

37. Olivia M, Nikraz H. Properties of fly ash geopolymer concrete designed by Taguchi method. Materials \& Design (1980-2015). 2012;36:191-198.

38. Kim KD, Han DN, Kim HT. Optimization of experimental conditions based on the Taguchi robust design for the formation of nano-sized silver particles by chemical reduction method. Chemical Engineering Journal. 2004;104(1-3):55-61.

39. Mehat NM, Kamaruddin S. Investigating the Effects of Injection Molding Parameters on the Mechanical Properties of Recycled Plastic Parts Using the Taguchi Method. Materials and Manufacturing Processes. 2011;26(2):202-209.

40. Lu S, Chen D, Wang X, Shao J, Ma K, Zhang L, et al. Real-time cure behaviour monitoring of polymer composites using a highly flexible and sensitive CNT buckypaper sensor. Composites Science and Technology. 2017;152:181-189.

41. Park SH, Lee CS. The difference in degree of conversion between light-cured and additional heat-cured composites. Operative Dentistry. 1996;21(5):213-217.

42. Daronch M, Rueggeberg FA, De Goes MF. Monomer conversion of pre-heated composite. Journal of Dental Research. 2005;84(7):663-667.
43. McElroy DL, Weaver FJ, Bridgman C. Thermal expansion of epoxy-fiberglass composite specimens. International Journal of Thermophysics. 1988;9(2):233-243.

44. Rudd RM, Ghafarian SR, Taherkhani A. The Effects of Post Curing Process on the Mechanical Properties of Glass Fiber/ Phenol -Formaldehyde Molded Composites. Journal of Basic and Applied Scientific Research. 2013;3(1s):36-39.

45. Dolez P, Marek M, Love BJ. Photopolymerizable acrylic resin: effect of curing time and temperature. Journal of Applied Polymer Science. 2001;82(3):546-554.

46. Kim H, Char K. Dielectric Changes During the Curing of Epoxy Resin Based on the Diglycidyl Ether of Bisphenol A (DGEBA) with Diamine. Bulletin of the Korean Chemical Society. 1999;20(11):1329-1334.

47. Wurster DE, Bhattacharjya S, Flanagan DR. Effect of Curing on Water Diffusivities in Acrylate Free Films as Measured via a Sorption Technique. AAPS PharmSciTech. 2007;8(3):E71. DOI: $10.1208 /$ pt0803071

48. Kozakiewicz J, Rokicki G, Przybylski J, Sylwestrzak K, Parzuchowski PG, Tomczyk KM. Studies on the effect of curing conditions on the curing rate and mechanical properties of moisture-cured poly(urethane-urea) elastomers containing oligocarbonate segments. Polimery Journal. 2011;56(78):564-570.

49. Bolasodun B, Nesbitt A, Wilkinson A, Day R. Effect of Curing Method On Physical And Mechanical Properties Of Araldite DLS 772 / 44 DDS Epoxy System. International Journal of Scientific \& Technology Research. 2013;2(2):12-18.

50. Hakimian E, Sulong AB. Analysis of warpage and shrinkage properties of injection-molded micro gears polymer composites using numerical simulations assisted by the Taguchi method. Materials \& Design. 2012;42:62-71.

51. Quiroga A, Marzocchi V, Rintoul I. Influence of wood treatments on mechanical properties of wood-cement composites and of Populus Euroamericana wood fibers. Composites Part B: Engineering. 2016;84:25-32.

52. Hoffman JIE. Biostatistics for Medical and Biomedical Practitioners. Oxford: Academic Press; 2015. 